\title{
A market comparison method evaluation model based on set pair analysis
}

\author{
Xiuli Wang ${ }^{1,}$, , Jun Lei ${ }^{2, b}$, Jie Bai ${ }^{2, c}$ and Hengkai $\mathrm{Li}^{2, \mathrm{~d}}$ \\ ${ }^{1}$ College of Economic Management, Jiangxi University of Science and Technology, Ganzhou \\ 341000, China \\ ${ }^{2}$ College of Architecture and Surveying Engineering, Jiangxi University of Science and Technology, \\ Ganzhou 341000, China \\ aitisher@126.com, b2471776198 @qq.com, 6ㅡㄴ.com
}

Keywords: Real Estate Evaluation; Set Pair Analysis; GIS; Model

\begin{abstract}
Appraisal model of estate market comparison approach existed uncertain problem, so a new appraisal model integration of GIS and set pair analysis was built. Firstly, using the GIS spatial analysis method quantified the real estate price impact factors. Then, its weights were calculated by entropy weight method. Lastly, we developed the application of appraisal estate price with set pair analysis and GIS technology, and calculated the some appraisal real estate prices. The result shows that the appraisal model can improve the efficiency of real estate appraisal and accuracy, and it will have widely prospect in rapid quantized real estate price.
\end{abstract}

\section{Introduction}

Market comparison method is the most widely used method in real estate appraisal[1], but in the process of evaluation, there are many uncertainty factors, the calculation of market comparison approach value mainly depends on the valuer's experience with subjectivity, which makes the appraisal result lack of dependability and credibility[2].To enhance the credibility of real estate valuation, some scholars proposed a number of improved model[3-5].The are mainly fuzzy mathematics method based on the regression of probability and statistics theory and fuzzy logic theory, the former is too much emphasis on the independence of system, and the latter is over-reliance on subjective experience, these two theories are both inadequate[6].Set pair analysis was proposed in 1989 by Chinese scholar keqin-zhao as a new theory of uncertainty[7], its core idea is to make a system analysis with certainty and uncertainty measure of objective things, thus handle the mixed uncertainty problems caused by fuzzy and random uncertainty with overall. zhou [9] and ye[6] take advantage of the set pair analysis to handle certainty and uncertainty relation in the process of market comparison method, in some way improve the uncertainty of the model, but the quantitation of real estate price impact factor mainly depends on the experts' score, uncertainties remained, which affects the accuracy of model. In recent years, some scholars use geographic information system (GIS) technology to extract and quantize influence factors [9-10], greatly improved the accuracy of quantitative factors. The GIS technology and set pair analysis theory, the combination of the two advantages to build a new valuation model which is expected to radically improve market comparison method valuation uncertainty problems, this article has carried on the exploration.

\section{Evaluation Model Building}

The thought of establishing a evaluated model is shown in figure 1.First of all, the use of GIS for data acquisition and management ability, to acquit and manage the trading case property, on the map, indicate the space position of trading case with the point, and establish the visual trading case database, the process of the data acquisition putted in storage. Based on the same way, the being estimated property database was established.Then, with a specific be estimated real estate as the center, search around a certain range of the same as to be estimated real estate structure, the same 
property rights of the trading case 4-7 as the comparable transaction case .The size of this range can be set, if in the largest setting range the search out the number of being estimated real estate is still less than 4, the need to add new trading case within the range around the be estimated house property; Next, to search out the comparable trading case, using GIS spatial analysis method, to quantify the price impact factor of its setting., treat for the be estimated property, using the same methods and standards for quantification; Finally, according to the quantized value, using the entropy weight method to determine the price impact factor weights, and amendment for the trading of comparable case time, on this basis, using set pair analysis model, calculate the contact between estimated real estate and trading case and similar-different-antithetical distance the distance size as weights based on price, calculate the final be estimated prices.

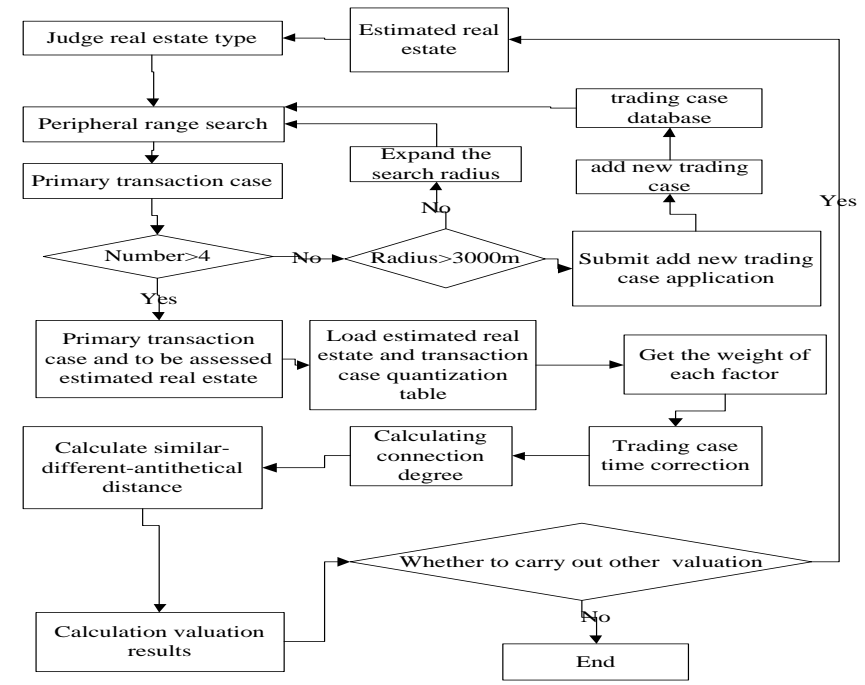

Figure 1 assessment model is established in this way of thinking

The effect of the housing property prices mainly includes two aspects.one is in a particular area the natural condition and social, economic, administrative and technical factors of regional characteristics. On the other hand, refers to the specific characteristics of real estate influence on property prices. The accurate quantification of the influence factors of the real estate price is an important factor to determine the accuracy of appraisal results. This model relies on the improvement of the real estate in the area of basic geographic spatial data and the analytic function of GIS to quantify the real estate price impact factor. Considering the different price factor index of distance will have a certain effect on property prices, for part of the impact factor index, the model adopt hierarchical query buffer to make quantitative results more accurate and reliable. All factors with 10 points, as shown in table 1 for house property influence factor and quantitative methods.

After the quantification is completed, if not satisfied with the result of quantitative, appraisers can quantify the results to fine-tune according to the specific case, make the quantitative result more reasonable.

This model uses the entropy method to determine the weight of each factor, which is an objective method of empowerment, based on the degree of variability of each factor, using information entropy calculate the index of entropy, and then by entropy effects on each indicator weighting factor correction, subjectivity and limitations can be avoided when the weight given to [14]. The method specific steps:

(1) For multiple comparable transaction case 15 impact factor quantitative score are arranged as shown in table 2.

In table $2, A_{j}(j=1,2, \ldots, n)$ represents the $j$-th case comparable transactions; $B_{i}(i=1,2, \ldots \ldots$ $\mathrm{m})$ represents the $\mathrm{i}$-th impact factor.

(2) Calculation of the i-th index value of comparable transactions proportion of cases in the j-th factor, Formula (1):

$$
p_{i j}=q_{i j} / \sum_{i=1}^{15} q_{i j}
$$


Table 1 Residential property factors and quantitative methods

\begin{tabular}{|c|c|}
\hline Impact factor & quantitative method \\
\hline $\begin{array}{l}\text { the distance } \\
\text { To } \operatorname{CBD}\left(U_{1}\right)\end{array}$ & $\begin{array}{l}\text { Shortest distances to the city center, } 10 \text { points for } 0 \text { to } 5 \mathrm{~km}, 8 \text { points for } 5 \text { to } 10 \mathrm{~km}, 5 \\
\text { points for } 10 \text { kilometers away. }\end{array}$ \\
\hline $\begin{array}{c}\text { transportation } \\
\text { convenient degree } \\
\left(U_{2}\right)\end{array}$ & $\begin{array}{l}\text { Each with } 1 \text { point for bus stations within } 500 \mathrm{~m} \text {,each with } 0.5 \text { point for bus route } \\
\text { through the site, } 2 \text { points for near the main road; each with } 0.6 \text { point for bus stations and } \\
\text { bus routes through the site from } 500 \mathrm{~m} \text { to } 800 \mathrm{~m} \text {,top } 10 \text { points. }\end{array}$ \\
\hline $\begin{array}{l}\text { Educational } \\
\text { mating }\left(U_{3}\right)\end{array}$ & $\begin{array}{l}3 \text { points for kindergarten around the house within } 600 \mathrm{~m}, 2 \text { points for primary school and } \\
\text { university, } 1 \text { point for kindergarten, primary school, university around the house from } \\
600 \mathrm{~m} \text { to } 1000 \mathrm{~m} \text {,top } 10 \text { points. }\end{array}$ \\
\hline $\begin{array}{l}\text { Recreation and } \\
\text { sports }\left(U_{4}\right)\end{array}$ & $\begin{array}{l}\text { Each with } 1.5 \text { points for amusement park, stadium, library and theatre within } 600 \mathrm{~m} \text {,each } \\
\text { with } 1 \text { point for amusement park,stadium,library and theatre around the house from } \\
600 \mathrm{~m} \text { to } 1000 \mathrm{~m} \text {, top } 10 \text { points. }\end{array}$ \\
\hline $\begin{array}{l}\text { living facilities } \\
\qquad\left(U_{5}\right)\end{array}$ & $\begin{array}{l}\text { Each with } 1.2 \text { points for supermarket,bank,shopping mall,hospital,farm.within } \\
600 \mathrm{~m} \text {,each with } 0.8 \text { point for the number of supermarket, banks, shopping malls, } \\
\text { hospitals, farms around the house from } 600 \mathrm{~m} \text { to } 1000 \mathrm{~m} \text {,top } 10 \text { points. }\end{array}$ \\
\hline $\begin{array}{c}\text { natural } \\
\text { environment }\left(U_{6}\right)\end{array}$ & $\begin{array}{l}\text { Each with } 5 \text { points for park and river within } 1000 \mathrm{~m} \text { around the house, reduce each with } \\
1 \text { point for highway, railway, urban main road within } 500 \mathrm{~m} \text {. top } 10 \text { points. }\end{array}$ \\
\hline $\begin{array}{l}\text { Building facilities } \\
\qquad\left(U_{7}\right)\end{array}$ & $\begin{array}{l}\text { Each with } 3 \text { points for water and electricity, each with } 1 \text { point for gas, broadband, cable } \\
\text { TV, air conditioning, parking lots, communications, disaster prevention system } \\
\text { and security system, clean. top } 10 \text { points. }\end{array}$ \\
\hline Newness rate $\left(U_{8}\right)$ & $\begin{array}{l}\text { With 8-10 points for good condition, with } 6-8 \text { point for basic good housing, with } 4-6 \\
\text { point for general damage to the housing, under } 4 \text { points for serious damage to the } \\
\text { housing and dangerous rooms. }\end{array}$ \\
\hline House style $\left(U_{9}\right)$ & $\begin{array}{l}\text { With } 10 \text { points for more than } 3 \text { rooms } 2 \text { hall and } 2 \text { guard, with } 8 \text { points for } 3 \text { rooms } 2 \\
\text { hall and a guard, with } 6 \text { points for } 2 \text { rooms } 2 \text { hall and a guard, with } 4 \text { points for } 2 \text { rooms } \\
\text { a hall and a guard, with } 2 \text { points for others. }\end{array}$ \\
\hline $\begin{array}{c}\text { orientation } \\
\left(U_{10}\right)\end{array}$ & $\begin{array}{l}\text { With } 10 \text { points for south, with } 8 \text { points for southeast, southwest, north and south, with } 6 \\
\text { points for east, with } 4 \text { points for west, northeast, with } 2 \text { points for north. }\end{array}$ \\
\hline floor $\left(U_{11}\right)$ & $\begin{array}{l}\text { No elevator: with } 10 \text { points for layer } 3 \text {, with } 8 \text { points for layer } 4 \text {, with } 6 \text { points for layers } \\
2 \text { and } 5 \text {, with } 4 \text { points for layer } 1 \text {, with } 2 \text { points for the top; Elevator: with } 10 \text { points for } \\
\text { layers } 25 \text { above, with } 8 \text { points for layers } 19 \text { to } 24 \text {, with } 6 \text { points for layers } 13 \text { to } 18 \text {, with } \\
4 \text { points for layers } 7 \text { to } 12 \text {, with } 2 \text { points for layers } 1 \text { to } 6 \text {. }\end{array}$ \\
\hline $\begin{array}{l}\text { district } \\
\text { environment } \\
\qquad\left(U_{12}\right)\end{array}$ & $\begin{array}{l}\text { With } 10 \text { points for optimal: more than } 30 \% \text { green rate, very quiet. With } 8 \text { points for } \\
\text { better: } 20 \% \text { - } 30 \% \text { green rate, quiet. With } 6 \text { points for general: } 15 \% \text { - } 20 \% \text { green rate, no } \\
\text { noise. With } 4 \text { points for inferior: } 10 \%-15 \% \text { green rate, big noise. With } 2 \text { points for bad: } \\
\text { less than } 10 \% \text { green rate, seriously noise.. }\end{array}$ \\
\hline $\begin{array}{l}\text { property } \\
\text { management } \\
\quad\left(U_{13}\right)\end{array}$ & $\begin{array}{l}\text { With } 10 \text { points for optimal: first-level management, all day security patrol, video } \\
\text { monitoring. With } 8 \text { points for better: second-level management, all day security patrol, } \\
\text { and video monitoring. With } 6 \text { points for general: second-level management, security } \\
\text { patrol. With } 4 \text { points for inferior: third-level management. With } 2 \text { points for bad: no } \\
\text { management. }\end{array}$ \\
\hline $\begin{array}{l}\text { ventilation and } \\
\text { lighting } \\
\left(U_{14}\right)\end{array}$ & $\begin{array}{l}\text { With } 10 \text { points for optimal: average } 8 \text { hours sunshine per day, window wall area above } \\
1 / 3 \text {, air convection. With } 8 \text { points for better: average } 6 \text { hours sunshine per day, window } \\
\text { wall area above } 1 / 4 \text {, air convection. With } 6 \text { points for general: average } 5 \text { hours sunshine } \\
\text { per day, window wall area above } 1 / 5 \text {, no air convection. With } 4 \text { points for inferior: } \\
\text { average } 2 \text { hours sunshine per day, window wall area above } 1 / 7 \text {, no air convection. With } \\
2 \text { points for bad: average below } 2 \text { hours sunshine per day or no window }\end{array}$ \\
\hline $\begin{array}{c}\text { Decoration } \\
\left(U_{15}\right) \\
\end{array}$ & $\begin{array}{l}\text { With 8-10 points for luxury decoration, with 6-8 points for fully decoration, with 4-6 } \\
\text { points for simple decoration, with 2-4 points for no decoration. }\end{array}$ \\
\hline
\end{tabular}


Table 2 Influence Factor quantification score list

$\begin{array}{crrllll} & A_{1} & A_{2} & \mathrm{~L} & A_{j} & \mathrm{~L} & A_{n} \\ B_{1} & q_{11} & q_{12} & \mathrm{~L} & q_{1 j} & \mathrm{~L} & q_{1 n} \\ B_{2} & q_{21} & q_{22} & \mathrm{~L} & q_{2 j} & \mathrm{~L} & q_{2 n} \\ \mathrm{M} & \mathrm{M} & \mathrm{M} & \mathrm{M} & \mathrm{M} & \mathrm{M} & \mathrm{M} \\ B_{i} & q_{i 1} & q_{i 2} & \mathrm{~L} & q_{i j} & \mathrm{~L} & q_{i n} \\ \mathrm{M} & \mathrm{M} & \mathrm{M} & \mathrm{M} & \mathrm{M} & \mathrm{M} & \mathrm{M} \\ B_{15} & q_{15,1} & q_{15,2} & \mathrm{~L} & q_{15, j} & \mathrm{~L} & q_{15, n}\end{array}$

(3) Calculate the j-th index of entropy, formula (2):

$$
e_{j}=-\frac{1}{\ln 15} \sum_{i=1}^{15} p_{i j} \ln p_{i j}
$$

(4) Calculate the entropy index of the j-th image, formula (3):

$$
w_{j}=\left(1-e_{j}\right) / \sum_{j=1}^{n}\left(1-e_{j}\right)
$$

For the weights of the 15 factors, and then normalized, get $U_{1} 、 U_{2} \ldots U_{15}$ corresponding weight vector formula (4):

$$
w=\left(w_{1}, w_{2}, \mathrm{~L}, \mathrm{w}_{15}\right)
$$

Cases in this model, Trading Case time correction according to the local statistical department of comparable transactions house price index cases one by one correction time, Get the $\mathrm{j}$-th time comparable transactions cases revised price for $\mathrm{P}_{\mathrm{j}}$

For each pair of the real estate price influence factor, there is only the similarities and differences, so this model only considers the same degree and the degree of difference. Be estimated property for $\mathrm{C}$, will be estimated property $\mathrm{C} i$-th characteristic factor quantitative value recorded $a \mathrm{~b}_{\mathrm{i}}$, Then $\mathrm{C}$ and comparable transactions Case $\mathrm{A}_{\mathrm{j}}$ Construction $\mathrm{n}$ collection, one by one to identify common characteristics of each collection, antagonistic properties, namely the same degree and differences in degree, and to establish in this issue of the expression $\mathrm{W}$ contact each characteristic factor in the collection, such as the formula (5):

$$
u_{i j}(w)=\frac{q_{i j}}{b_{i}}+\frac{q_{i j}-b_{i}}{b_{i}} i
$$

In the type: $\mathrm{u}_{\mathrm{ij}}(\mathrm{w})$ is the contact degree of impact factor I from collection of the J-th comparable transaction case and to assess property $C$, The ratio of $\frac{q_{i j}}{b_{i}}$ called the same; the ratio of $\frac{q_{i j}-b_{i}}{b_{i}}$ called difference degree.

According to (4) weight $w$ as the impact factor of the property calculation, can calculate the average weighted connection degree $u_{j}(w)$ with the collection of the J-th comparable transaction case and to assess property $\mathrm{C}$, as shown in equation (6):

$$
u_{j}(w)=\sum_{i=1}^{15} w_{i}\left(\frac{q_{i j}}{b_{i}}+\frac{q_{i j}-b_{i}}{b_{i}} i\right)
$$

And then calculate the comparable transaction case $\mathrm{J}$ and the assess property's distance $\rho_{j}$, as shown in equation (7):

$$
\rho_{j}=\sqrt{\left(\sum_{i=1}^{15} \frac{w_{i} q_{i j}}{b_{i}}\right)^{2}+\left(\sum_{i=1}^{15} w_{i} \frac{q_{i j}-b_{i}}{b_{i}}\right)^{2}}
$$

The price(p) of C's can be corrected by time $\mathrm{P}_{\mathrm{j}}$ and similar-different-antithetical distance $\rho_{j}$ show, as shown in equation(8): 


$$
P=\sum_{j=1}^{n} \frac{P_{j}}{\rho_{j}} / \sum_{j=1}^{n} \frac{1}{\rho_{j}}
$$

\section{Model Application}

According to the above model, regarding ArcEngine as GIS software platform, c\# as the programming language, programming for the model, and based on this model to develop the set pair analysis platform for the real estate appraisal system. In order to verify the accuracy of the model and the practicability of the system, the paper takes Ganzhou city as the test data and real estate transaction data as the test data, and uses the system to carry on the concrete appraisal practice of a residential real estate in Ganzhou. The specific operation process is as follows.

First of all, using transaction case collection function collect enough of the recent real estate transactions case, establishing trading case.After the establishment of the transaction case database and to assess the real estate, first select the need for quantitative property, according to the prompt, using GIS analysis method, to quantify the influence factors one by one, After quantification, The valuation staff can be adjusted according to the specific circumstances, to quantify the results, but fine-tuning must be conducted under certain principles and scope, in order to reflect the unity of scientific and artistic value of real estate appraisal. Uploading the quantitative results submitted to the database, using the same method, in order to evaluate the influence factors of the real estate and the transaction case one by one. Among them, The traffic convenience of the property is shown in Figure 2, according to the quantitative criteria of Table 1, this method uses a hierarchical buffer query method.

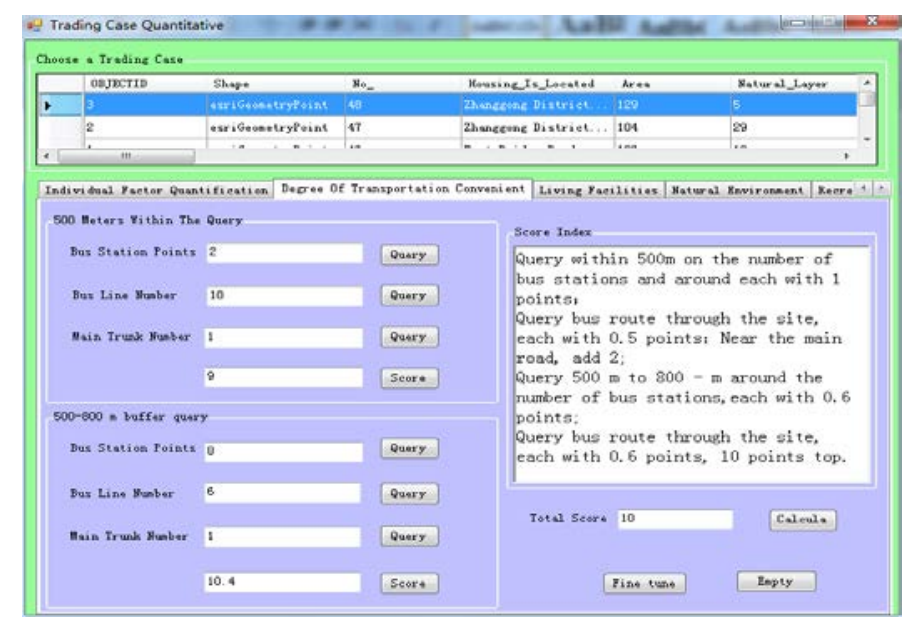

Figure 2 Trading case quantitative interface

After the be estimated real estate quantify with the trading case, as shown in figure 1 can evaluate Ganzhou city some which is to be estimated according to the diagram of train establish of the assessment model shown in figure 1 .Open the evaluation interface ,for real estate as the center, select out the comparable trading case within a range around the case, the final screening of the five with the same as the real estate structure, and the transaction time is close to the transaction cases as a transaction case.And from the database query be estimated property and comparable trading case of the quantitative results, according to the calculation model of entropy weight method calculate the weight of influence factors. Then correct the trading cases and the trading time of the estimated real estate, the transaction price will be unified to the same time as the real estate. Using set pair analysis model to calculate the similar-different-antithetical distance of the estimated real estate with each trading cases, finally calculate be estimated prices. Finally, archive and print out the results of valuation, the system can automatically output word format valuation report, only need a little editing can be used as a formal valuation report provided to the client. the be estimated property after the price evaluation of this system , the price of 5016 yuan $/ \mathrm{m}^{2}$, and the actual transaction price is 5150 yuan $/ \mathrm{m}^{2}$, and real estate prices close to the actual transaction , it show that 
the model has high credibility.

\section{Conclusion}

Set pair analysis model provides a new train of thought for real estate appraisal, which can deal with all kinds of certainty and uncertainty problems in the process of evaluation, overcome the limitations of traditional evaluation market comparison method; Integration of GIS and set pair analysis, give play to the GIS data acquisition, management, spatial analysis and model integration advantages, on the one hand, for the trading case and be estimated real estate management and accurate quantitative provide platform , on the other hand, integrate seamless for the method of with the set pair analysis model , opens up a new method of real estate evaluation; The model application practice shows that the evaluation model with high accuracy, can be competent to the evaluation of real estate market. The informationize evaluation system developed can greatly improve the efficiency of real estate evaluation, rapidly booming in the real estate pricing will having wide application prospects in the rapidly quantificational pricing of the real estate.

\section{References}

[1] Pagourtzi E, Assimakopoulos V, Hatzichristos T, et al. Real estate appraisal: a review of valuation methods[J]. Journal of Property Investment \& Finance, 2003, 21(4): 383-401

[2] Cai Jian-hong, Zhu Dao-lin. Study on the uncertainty of market comparison method[J].Land science in China, 2015, 29(4):57-65

[3] Xiao Zheng-ming, Wang Hai-sen. Improvement of real estate market comparison method based on fuzzy mathematics theory:Take Xiamen city as an example[J].Resources and Industry,2014, 16(6):44-48

[4] Chen Liang-qiong, Zhang Zong-ling.Research on the market comparison method based on the characteristic price theory [J]. Journal of Xinyang Normal University: Natural Science Edition, 2012, 24(4): 553-557.

[5] Dong Xiao-jie. Improvement of real estate appraisal market comparison method based on Fuzzy Mathematics [D]. Liaoning University, 2014.

[6] YE Qing, Wang Quan-feng, Lai Rong-ying.Research on the application of market comparison method based on Set Pair Analysis[J]. Practice and cognition of Mathematics, 2009, 39(19): 70-75.

[7] Zhao Ke-qin.Set pair analysis and its preliminary application [M]. Hangzhou: Zhejiang science and Technology Press, 2000.

[8] Wang Xin-fan, Wang Jian-qiang, Yang Xiao-juan. A group decision making method based on the relation of the two elements of the information[J].Journal of Management Engineering, 2014 (1): 202-208.

[9] Pagourtzi E, Nikolopoulos K, Assimakopoulos V. Architecture for a real estate analysis information system using GIS techniques integrated with fuzzy theory [J]. Journal of Property Investment \& Finance, 2006, 24(1): 68-78

[10] García N, Gámez M, Alfaro E. ANN+ GIS: An automated system for property valuation [J]. Neurocomputing, 2008, 71(4): 733-742. 